\title{
Evaluation of a quality improvement bundle aimed to reduce opioid prescriptions after Cesarean delivery: an interrupted time series study

\author{
Évaluation d'un ensemble d'améliorations de la qualité visant à \\ réduire les ordonnances d'opioïdes après un accouchement par \\ césarienne : une étude de séries chronologiques interrompues
}

\author{
Isabelle Laksono, BSc · John Matelski, MSc $\cdot$ David Flamer, MD $\cdot$ Shira Gold, MD · \\ Amanda Selk, MD, MSc (D)
}

Received: 10 February 2021/Revised: 29 June 2021/Accepted: 23 September 2021 / Published online: 8 November 2021

(C) The Author(s) 2021

\begin{abstract}
Purpose To evaluate whether opioid prescriptions at discharge after Cesarean delivery decreased following implementation of a quality improvement bundle.

Methods A quality improvement bundle was instituted at Mount Sinai Hospital in Toronto. Interventions included opioid prescribing instructions in resident orientation, nursing and patient education, and standard electronic prescriptions. We used an interrupted time series study design and included patients who had a Cesarean delivery
\end{abstract}

Supplementary Information The online version contains supplementary material available at https://doi.org/10.1007/s12630021-02143-7.

\section{Laksono, BSc}

Faculty of Medicine, University of Toronto, Toronto, ON, Canada

J. Matelski, MSc

Biostatistics Research Unit, University Health Network,

Toronto, ON, Canada

D. Flamer, MD

Department of Anesthesiology and Pain Medicine, Mount Sinai Hospital, University of Toronto, Toronto, ON, Canada

S. Gold, MD

Department of Obstetrics and Gynaecology, University of Toronto, Toronto, ON, Canada

\section{A. Selk, MD, MSc ( $\square)$}

Department of Obstetrics and Gynaecology, Mount Sinai Hospital, University of Toronto, 700 University Ave, 3rd Floor, Toronto, ON M5G1Z5, Canada

e-mail: amanda.selk@utoronto.ca six months pre intervention and six months post intervention. Primary outcome data (opioids prescribed at discharge in morphine milliequivalents [MME]), were aggregated (averaged) by calendar week and analyzed using interrupted time series. Secondary outcomes were assessed using bivariate methods and included opioid use for breakthrough pain in hospital, and amount of opioids prescribed by prescriber specialty and training level.

Results We included 2,578 women in our analysis. Based on the segmented regression analysis, prescribed opioids decreased from 97.6 MME in 2018 to 35.8 MME in 2019 (difference in means, - 61.7; 95\% confidence interval [CI], -72.2 to $-51.3 ; P<0.001)$, and this decrease was sustained over the study period. Post intervention, there were no visits to our postnatal assessment clinic for inadequate pain control.

Conclusion A quality improvement bundle was associated with a marked and sustained decrease in discharge prescriptions of opioids post Cesarean delivery at a large Canadian tertiary academic hospital.

\section{Résumé}

Objectif Déterminer si les ordonnances d'opioïdes au congé après un accouchement par césarienne avaient diminué à la suite de la mise en place d'un ensemble d'améliorations de la qualité.

Méthode Un ensemble d'améliorations de la qualité a été mis en place à l'Hôpital Mount Sinai de Toronto. Les interventions comprenaient des instructions de prescription d'opioïles pendant l'orientation des résidents, la formation des soins infirmiers et des patients, ainsi que des ordonnances électroniques standard. Nous avons 
utilisé un plan d'étude de séries chronologiques interrompues et inclus des patientes ayant accouché par césarienne six mois avant et six mois après l'intervention. Les données sur le critère d'évaluation principal (soit les opioïdes prescrits au congé en équivalents de morphine en milligrammes [EMM]) ont été agrégées (moyennes) par semaine civile et analysées à l'aide de séries chronologiques interrompues. Les critères d'évaluation secondaires ont été estimés à l'aide de méthodes bivariées et comprenaient l'utilisation d'opioïdes pour les accès douloureux paroxystiques à l'hôpital, ainsi que la quantité d'opiö̈les prescrits en fonction de la spécialité et du niveau de formation du prescripteur.

Résultats Nous avons inclus 2578 femmes dans notre analyse. Selon l'analyse de régression segmentée, les opioüdes prescrits sont passés de 97,6 EMM en 2018 à 35,8 EMM en 2019 (différence de moyennes, - 61,7; intervalle de confiance [IC] à $95 \%,-72,2 \grave{a}-51,3 ; P<0,001)$, et cette diminution s'est maintenue au cours de la période d'étude. Après l'intervention, il n'y a pas eu de visites à notre clinique d'évaluation postnatale pour remédier à un soulagement inadéquat de la douleur.

Conclusion Un ensemble d'améliorations de la qualité a été associé à une diminution marquée et soutenue des ordonnances d'opiö̈les après les accouchements par césarienne dans un grand hôpital universitaire tertiaire canadien.

Keywords Narcotics - Cesarean delivery - Obstetrics · Analgesia · Opioids

\section{Introduction}

Opioid prescribing practices have come under scrutiny in recent years, in both the scientific community and the general public. The USA and Canada are the first and second-largest per capita consumers of opioids worldwide, with 191 million prescriptions dispensed to Americans in 2017 and 20 million prescriptions dispensed to Canadians in $2016 .^{1-3}$ In addition, a 2019 multicentre study showed that surgical patients in the USA and Canada receive larger prescription amounts than their Swedish counterparts for the same four surgeries. ${ }^{4}$ While opioids can play an important role in postoperative pain management, they come with risks of adverse events, dependence and addiction, and misuse and diversion. Postoperative opioid use has been shown to be a risk factor for chronic opioid use. $^{5-7}$ Physicians have been called upon to reduce opioid prescribing in the wake of the opioid crisis. ${ }^{8-10}$ In recent years, Health Quality Ontario and the Institute for Clinical Systems Improvement determined that there was an immediate need to integrate quality improvement (QI) plans for postoperative prescribing of opioid pain medication. $^{11,12}$

Cesarean delivery is the most commonly performed inpatient surgery in Canada and the USA, with procedures exceeding 1.2 million and 100,000 per year, respectively. ${ }^{13,14}$ While opioids are frequently prescribed following Cesarean delivery, numerous studies have shown that this population is prescribed opioids in excess of what is typically required. ${ }^{15-20}$ Education-based QI initiatives for prescribers, nurses, and patients have been shown to successfully reduce opioid prescribing in this patient population. $^{18,21,22}$ In 2019, we performed a randomized controlled trial, which showed that opioid prescribing following elective Cesarean delivery could be reduced by $50 \%$ at our centre without compromising patient satisfaction. ${ }^{15}$ We also showed that patients who did not require opioids in hospital did not require an opioid prescription at discharge. ${ }^{15}$

In 2018, the standard opioid prescription following Cesarean delivery was 201 -mg hydromorphone tablets, or 100 morphine milliequivalents (MME), similar to other academic centres in Toronto. This quantity resulted in excess opioid in the community, creating concern for misuse and diversion. ${ }^{15}$ Following dissemination of results of our study, in conjunction with the Opioid Safety Committee, the hospital implemented a bundled QI intervention from January to June 2019 that included the following: 1) resident education, 2) postpartum nursing education, 3) posters, 4) patient educational materials, and 5) electronic discharge prescriptions. The objective of this study was to assess whether there has been a decrease in opioid prescribing after Cesarean delivery at Mount Sinai Hospital following implementation of a QI bundle of interventions aimed at decreasing opioid prescribing. Our hypothesis is that opioid prescribing post Cesarean delivery has decreased following QI bundle implementation.

\section{Methods}

Approval for this study was obtained from the Mount Sinai Hospital Research Ethics Board (REB \#20-0043-C). We followed the Standards for Quality Improvement Reporting Excellence (SQUIRE 2.0) guidelines. $^{23}$ Mount Sinai Hospital is an urban tertiary obstetrical centre with over 2,500 Cesarean deliveries performed annually. As an academic centre, discharge prescriptions are typically written by residents, including those from obstetrics, family medicine, anesthesia, and radiology program specialties. During the preintervention period, 30 obstetric staff, 32 off-service residents, nine obstetrics residents, and two advanced obstetrics fellows contributed to patient care. During the postintervention period, 30 
obstetric staff, 31 off-service residents, 15 obstetric residents, and three advanced obstetric fellows contributed to patient care. In Canada, residents traditionally complete five postgraduate years (PGY) of training with the exception of family medicine residents who complete two PGYs. Standard in-hospital opioid orders for breakthrough pain did not change between the pre- and postintervention periods and were either 1) 2-mg morphine $i \mathrm{v} / \mathrm{sc}$ maximum three doses in the first $24 \mathrm{hr}$ postpartum and 10-mg morphine tablets or 2) $0.4-\mathrm{mg}$ hydromorphone $i v / s c$ maximum three doses in the first 24 $\mathrm{hr}$ postpartum and 2-mg hydromorphone tablets. Nonopioids included in the order set in hospital also remained the same throughout the study period and included 50-mg diclofenac po (maximum nine doses) and 1,000-mg acetaminophen po (maximum 12 doses). The QI intervention bundle aimed at reducing opioid prescribing in patients following Cesarean delivery at Mount Sinai Hospital included the following:

1) At orientation, all obstetric and off-service residents were told to not routinely give opioid prescriptions at discharge, but to look at whether opioids were required by individual patients in hospital for breakthrough pain. If none were used, opioid prescriptions were not to be given. If opioids were used, residents were instructed to prescribe a maximum of ten 1-mg hydromorphone tablets if hydromorphone was used, or ten $10-\mathrm{mg}$ morphine tablets if morphine was used. This information was also included in the resident orientation manual.

2) Postpartum nurses were given education about pain management after discharge. This included reassurance that Cesarean delivery patients could be discharged without opioids, and guidance on counselling patients about managing mild to moderate pain (anti-inflammatories and acetaminophen) or severe pain (opioids) if required.

3) Posters were placed in the nursing stations on the postpartum wards with recommendations on how to discuss opioids as part of a pain management strategy with patients. These reminders focused on patient understanding and expectations, different types of postoperative pain, pharmacologic and nonpharmacologic alternatives to opioid therapy, and recommendations to provide only the necessary quantity of pain medications at discharge (Electronic Supplementary Material [ESM] eFig. 1).

4) Patients were given educational material about postpartum pain management, which included information about the different classes of pain medications prescribed, guidance for when to take these medications and how to reduce the dose as healing occurs, and advice about common side effects. Information about storing medication safely at home and proper disposal was also provided (ESM eFig. 2).

5) Electronic discharge prescriptions replaced paper prescriptions across the hospital with the standard post-Cesarean discharge prescription, if requiring opioids, consisting of ten tablets of 10-mg of morphine or five tablets of 1-mg hydromorphone. Prescribers were then able to actively change the prescription amount if needed. Prescribing instructions for non-opioid analgesics did not change and included 28 tablets of 500-mg acetaminophen and 14 tablets of 500-mg naproxen.

We used an interrupted time series design with weekly periods to compare changes in outcomes among all patients who had a Cesarean delivery at Mount Sinai Hospital between 1 July 2018 to 31 December 2018 pre intervention and 1 July 2019 to 31 December 2019 post intervention. Our approach to sample size was pragmatic and included all Cesarean deliveries during the specified time periods. Six-month periods were chosen to be able to observe month to month variation along with a potential sustained difference in prescribing patterns. The bundled QI intervention was implemented from 1 January 2019 to 30 June 2019. The patient list was provided by the health records department as all charts with surgeries undergo mandatory coding. Patients with missing outcome data, with chronic opioid use documented in their electronic medical record, or who were transferred to another hospital prior to discharge were excluded from the study.

Demographic and clinical data, including opioid prescriptions at discharge, were extracted from Cerner PowerChart electronic medical records (Cerner Corporation, North Kansas City, MO, USA) by a single reviewer from May to August 2020. The following patient demographics were collected: maternal age at delivery, gravida, parity, gestation number, and Cesarean delivery number. Clinical data included were: length of hospital stay, incision type, concomitant procedures performed, inhospital opioid usage for breakthrough pain, discharge prescription, and prescriber residency program specialty and level of training. A second reviewer validated $10 \%$ of randomly selected medical records.

The primary outcome was the amount of opioids prescribed at discharge in MME. All opioid quantities were converted to MME. ${ }^{24}$ Our process measure was the percent of patients receiving an electronic discharge prescription and our balancing measure was whether there were pain management visits in the postnatal clinic. Secondary outcomes included whether opioids were used for breakthrough pain in hospital, and prescribing patterns by provider according to residency program specialty and 
level of training. Subjects with missing primary outcome data were excluded from analysis.

Descriptive statistics are presented as mean (standard deviation [SD]) or median [interquartile range (IQR)]; the Shapiro-Wilk test was used to assess evidence against the assumption of normality. Comparisons between intervention periods were made using independent sample $t$ tests or Wilcoxon rank sum tests based on this assessment. Categorical variables are described using cell counts and percentages. The Chi square test or Fisher's exact test were used to compare categorical variables between intervention periods; if the expected cell counts were less than 5 in $20 \%$ or more of the cells, or if any one cell had an expected count less than 1, then Fisher's exact test was used. ${ }^{22}$ The Wilson's score method was used to construct confidence intervals for differences in proportions.

Primary outcome data (opioids prescribed at discharge in MME) were aggregated (averaged) by calendar week and analyzed using an interrupted time series. An AR1 correlation structure was used to account for temporal autocorrelation and parameter estimation was performed using restricted maximum likelihood. The generalized least squares model (implemented in $\mathrm{R}$ package nlme) was chosen for the analysis to allow for weighting of the weekly data points by the number of discharges that week, heterogeneity in residual variance among the two phases, and estimation of the AR1 autocorrelation parameter. We report the estimated level change and pre/post slopes with 95\% confidence intervals (CIs) and Wald test $P$ values. A sensitivity analysis using patient level outcome and covariate data was performed and similarly reported (see ESM eTable). All analyses were performed using $\mathrm{R}$ statistical software ( $\mathrm{R}$ version 3.6.2; $\mathrm{R}$ Foundation for Statistical Computing, Vienna, Austria). Alpha $=0.05$ was taken as the threshold for statistical significance.

\section{Results}

All 2,656 patients who underwent Cesarean delivery at Mount Sinai Hospital during the study period were screened. Of these patients, 2,578 met the study inclusion criteria and were included in our analysis (Fig. 1). A total of $78(2.9 \%)$ patients were excluded. Four patients were excluded in the preintervention group while 74 patients were excluded in the postintervention group, mostly for missing outcome data $(n=70 ; 94.6 \%)$. The reasons for exclusion are listed in Fig. 1. Post intervention, 95\% of patients received electronic prescriptions and there were no visits to the postnatal assessment unit for pain control. Obstetricians were asked if there were extra visits or phone calls postpartum regarding pain management and no change was reported. The preintervention $(n=1,352$;
$52.4 \%)$ and postintervention groups $(n=1,226 ; 47.6 \%)$ were similar in all demographic, surgical, and obstetrical characteristics (Table 1). The mean (SD) maternal age was 34.4 (4.8) yr. The majority of patients were gravida two or more and parity one. Overall, $94.6 \%$ of pregnancies were single gestations. In terms of surgical characteristics, this was the first Cesarean delivery for $64.9 \%$ of patients, and more than $60 \%$ of procedures were elective (scheduled). Pfannenstiel incisions were used in $94.7 \%$ of procedures and $12.8 \%$ of women had a concomitant procedure completed. The median length of hospital stay was two days.

Using segmented regression analysis for the primary outcome, opioids prescribed decreased from 97.6 MME in 2018 to 35.8 MME in 2019 (difference in means, - 61.7; 95\% CI, -72.2 to $-51.3 ; P<0.001$ ) (Table 2). The amount of opioid prescribed was consistent from month to month in the six months pre intervention and was sustained and consistent for the six months post intervention (Fig. 2). Overall, the unadjusted percentage of patients receiving an opioid prescription at discharge decreased significantly from $97.6 \%$ to $53.9 \%$ (difference, $-43.7 \%$; 95\% CI, -46.7 to $-40.7 ; P<0.001$ ) (Table 3). The median [IQR] total amount of prescribed opioids at discharge also decreased significantly from 100 [100-100] MME to 25 [0-50] MME $(P<0.001)$. In terms of type of opioid, preintervention prescriptions given were hydromorphone $1,294 / 1,320$ (98.0\%), oxycodone 20/1,320 (1.5\%) and morphine $6 / 1,320(0.5 \%)$. Post intervention, opioid prescriptions were 393/661 (59.5\%) hydromorphone, 253/661 (38.3\%) morphine, and 15/661 (2.3\%) oxycodone. Post intervention, prescriber training level $(P<0.001)$ and program specialty $(P<0.001)$ were associated with the amount of opioid prescribed (Table 4). There was no significant change in the proportion of patients using opioids in hospital (difference, $-2.5 \%$; $95 \%$ CI, -1.3 to $6.4 ; P=0.20$ ). Pre intervention, receiving opioids in hospital was not associated with whether a patient received an opioid prescription at discharge $(97.5 \%$ vs $97.8 \%$, respectively; $P=0.87$ ) (Table 5).

In both the preintervention and postintervention groups, prescriber level of training was associated with differences in the amount of opioid prescribed at discharge $(P<0.001)$ (Table 4). In the preintervention group, third-year trainees prescribed the lowest amount of opioids while attending physicians prescribed the highest. In the postintervention group, first-year residents and advanced obstetrical fellows prescribed the least amount of opioid at discharge, while attending physicians prescribed the most.

Prior to our bundled QI intervention, prescriber program specialty was not associated with the amount of opioid prescribed at discharge $(P=0.68)$ (Table 4$)$. Nevertheless, in the postintervention group, prescriber specialty was 


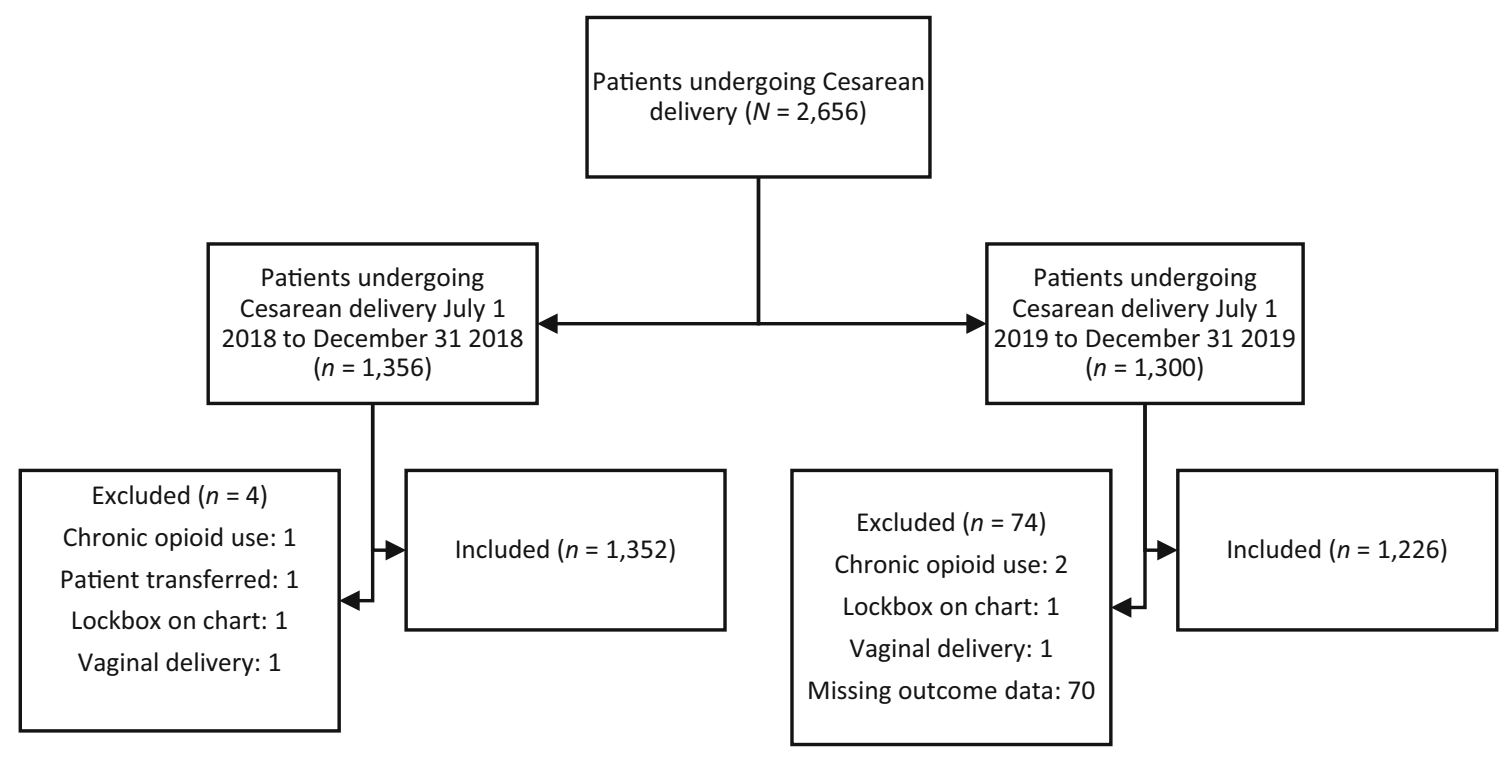

Fig. 1 Flow diagram of patients included in the bundled quality improvement intervention analysis before and after intervention implementation.

associated with a change in opioids prescribed $(P=0.002)$. Nurse practitioners and family medicine prescribers provided the fewest opioids at discharge, while obstetrical and radiology prescribers provided the most.

\section{Discussion}

We designed and successfully implemented a bundled QI intervention that was associated with a 61.7 MME decrease in opioid prescribed at discharge following Cesarean delivery. Post intervention, the amount of opioid prescribed at discharge was associated with whether or not opioids were used for breakthrough pain in hospital.

Quality improvement interventions require adherence to support improved outcomes. In our study, $95 \%$ of patients received electronic prescriptions post intervention, suggesting a high intervention fidelity. Hydromorphone was the most commonly prescribed opioid in both groups. Nevertheless, morphine was prescribed more frequently after QI bundle implementation, likely because morphine was included in the automatic electronic order set. The increased correlation between in-hospital opioid use and opioids prescribed at discharge also suggests a change in practice occurred to reflect in-hospital use in prescribing patterns. As our interventions were bundled, we are unable to discern the opioid reduction attributed to each of the following components: (1) resident education, (2) postpartum nursing education, (3) posters, (4) patient educational materials, and (5) electronic discharge prescriptions. Historically, education initiatives are often found to be a weak factor in QI initiatives. ${ }^{25}$ The effects of nursing and patient education are difficult to assess individually, but are important as postintervention nursing no longer standardly called residents for a discharge opioid prescriptions, and repeat Cesarean delivery patients who were given opioids at their first surgery no longer automatically received them at their repeat Cesarean delivery. We suspect that observed differences on discharge prescriptions were largely due to electronic prescriptions, as several studies have shown that electronic prescriptions with lower defaults are associated with lower opioid prescriptions. ${ }^{26,27}$ To our knowledge, there were no other opioid prescribing recommendation changes for this patient population during this study period. Nevertheless, in Ontario, there was a $4.9 \%$ decrease in new opioid prescriptions for pain in 2019 compared with in 2018, which may have contributed to some of the decrease in prescribing observed. ${ }^{28}$ Notably, our study showed a greater decrease than the provincial average, which our QI bundle may have contributed to.

Our intervention also showed an association between the amount of opioid prescribed at discharge and whether opioids were used for breakthrough pain in hospital. This association is consistent with promoting a tailored approach to prescribing, as studies have shown that women who do not require opioids in hospital have adequate pain control and are less likely to require opioids at discharge. ${ }^{18}$ Our results showed that, post intervention, residents who completed one PGY and advanced obstetric fellows prescribed the fewest opioids. This may be a result of junior residents having more time to attend education sessions and being newly trained in an environment with novel protocols in place, making them more likely to adopt new prescribing practices compared with senior residents, maternal fetal medicine fellows, and staff physicians who 
Table 1 Maternal demographic data of women undergoing Cesarean delivery before and after a bundled quality improvement intervention aimed at reducing postoperative opioid prescribing

\begin{tabular}{|c|c|c|c|c|}
\hline Characteristic & $\begin{array}{l}\text { Total } \\
N=2,578\end{array}$ & $\begin{array}{l}\text { Pre intervention } \\
n=1,352\end{array}$ & $\begin{array}{l}\text { Post intervention } \\
n=1,226\end{array}$ & $P$ value \\
\hline Age (year), mean (SD) & $34.4(4.8)$ & $34.2(4.9)$ & $34.5(4.8)$ & 0.18 \\
\hline \multicolumn{5}{|l|}{ Gravida } \\
\hline 1 & $931(36.1 \%)$ & $487(36.0 \%)$ & $444(36.2 \%)$ & \multirow[t]{2}{*}{0.95} \\
\hline 2 or more & $1,647(63.9 \%)$ & $865(64.0 \%)$ & $782(63.8 \%)$ & \\
\hline \multicolumn{5}{|l|}{ Parity } \\
\hline 1 & $1,367(53.0 \%)$ & $695(51.4 \%)$ & $672(54.8 \%)$ & \multirow[t]{2}{*}{0.09} \\
\hline 2 or more & $1,211(47.0 \%)$ & $657(48.6 \%)$ & $554(45.2 \%)$ & \\
\hline \multicolumn{5}{|l|}{ Multiple gestation } \\
\hline No & $2,438(94.6 \%)$ & $1,285(95.0 \%)$ & $1,153(94.0 \%)$ & \multirow[t]{2}{*}{0.30} \\
\hline Yes & $140(5.4 \%)$ & $67(5.0 \%)$ & $73(6.0 \%)$ & \\
\hline \multicolumn{5}{|l|}{ Number of Cesarean deliveries } \\
\hline 1 & $1,674(64.9 \%)$ & $871(64.4 \%)$ & $803(65.5 \%)$ & \multirow[t]{2}{*}{0.60} \\
\hline 2 or more & $904(35.1 \%)$ & $481(35.6 \%)$ & $423(34.5 \%)$ & \\
\hline \multicolumn{5}{|l|}{ Indication } \\
\hline Emergency & $1,019(39.5 \%)$ & $527(39.0 \%)$ & $492(40.1 \%)$ & \multirow[t]{2}{*}{0.58} \\
\hline Elective & $1,559(60.5 \%)$ & $825(61.0 \%)$ & $734(59.9 \%)$ & \\
\hline \multicolumn{5}{|l|}{ Incision type } \\
\hline Pfannenstiel & $2,441(94.7 \%)$ & $1,282(94.8 \%)$ & $1,159(94.5 \%)$ & \multirow[t]{3}{*}{0.54} \\
\hline Midline or $\mathrm{T}$ & $49(1.9 \%)$ & $28(2.1 \%)$ & $21(1.7 \%)$ & \\
\hline High transverse & $88(3.4 \%)$ & $42(3.1 \%)$ & $46(3.8 \%)$ & \\
\hline \multicolumn{5}{|l|}{ Concomitant procedure } \\
\hline No & $2,249(87.2 \%)$ & $1,191(88.1 \%)$ & $1,058(86.3 \%)$ & \multirow[t]{2}{*}{0.19} \\
\hline Yes & $329(12.8 \%)$ & $161(11.9 \%)$ & $168(13.7 \%)$ & \\
\hline Length of hospital stay (days), median [IQR] & $2[2,3]$ & $2[2,3]$ & $2[2,3]$ & 0.19 \\
\hline
\end{tabular}

All numbers are $n(\%)$ unless otherwise specified. $P$ values are from the Chi square test, Student's $t$ test, and Wilcoxon rank sum test. Normality was determined using the Shapiro-Wilk test.

$\mathrm{IQR}=$ interquartile range; $\mathrm{SD}=$ standard deviation

Table 2 Segmented regression model

\begin{tabular}{lclc}
\hline & Estimate (MME) & $95 \%$ CI & $P$ value \\
\hline Pre intervention & 97.6 & 92.8 to 102.4 & $<0.001$ \\
Post intervention & -61.7 & -72.2 to -51.3 & $<0.001$ \\
Pre intervention: week & 0.1 & -0.2 to 0.4 & 0.54 \\
Post intervention: week & -0.1 & -0.8 to 0.6 & 0.85 \\
\hline
\end{tabular}

The segmented regression was generated using generalized least squares regression model with data grouped by week in $\mathrm{R}$ statistical software. The "intervention: week" terms refer to the effect of week in each period.

$\mathrm{CI}=$ confidence interval; $\mathrm{MME}=$ morphine milliequivalents

were the highest opioid prescribers post intervention. Advanced obstetrical fellows act as hospitalists on postpartum wards at our institution and spend more time there than other trainees do, which may account for more judicious prescribing practices.
System-level barriers to reduce opioid overprescribing exist, such as cultural expectations of pain control and lack of clinical guidelines. Ladha et al. showed that, for the same routine surgeries, over $70 \%$ of opioid prescriptions were filled by patients in Canada and the USA, while only $11 \%$ were filled by patients in Sweden. ${ }^{4}$ At our site, we 
Fig. 2 Segmented regression model of average opioids prescribed at discharge grouped by week in morphine milliequivalents (MME) from July to December in 2018 and 2019. Shaded regions denote the 95\% confidence band for each segment.

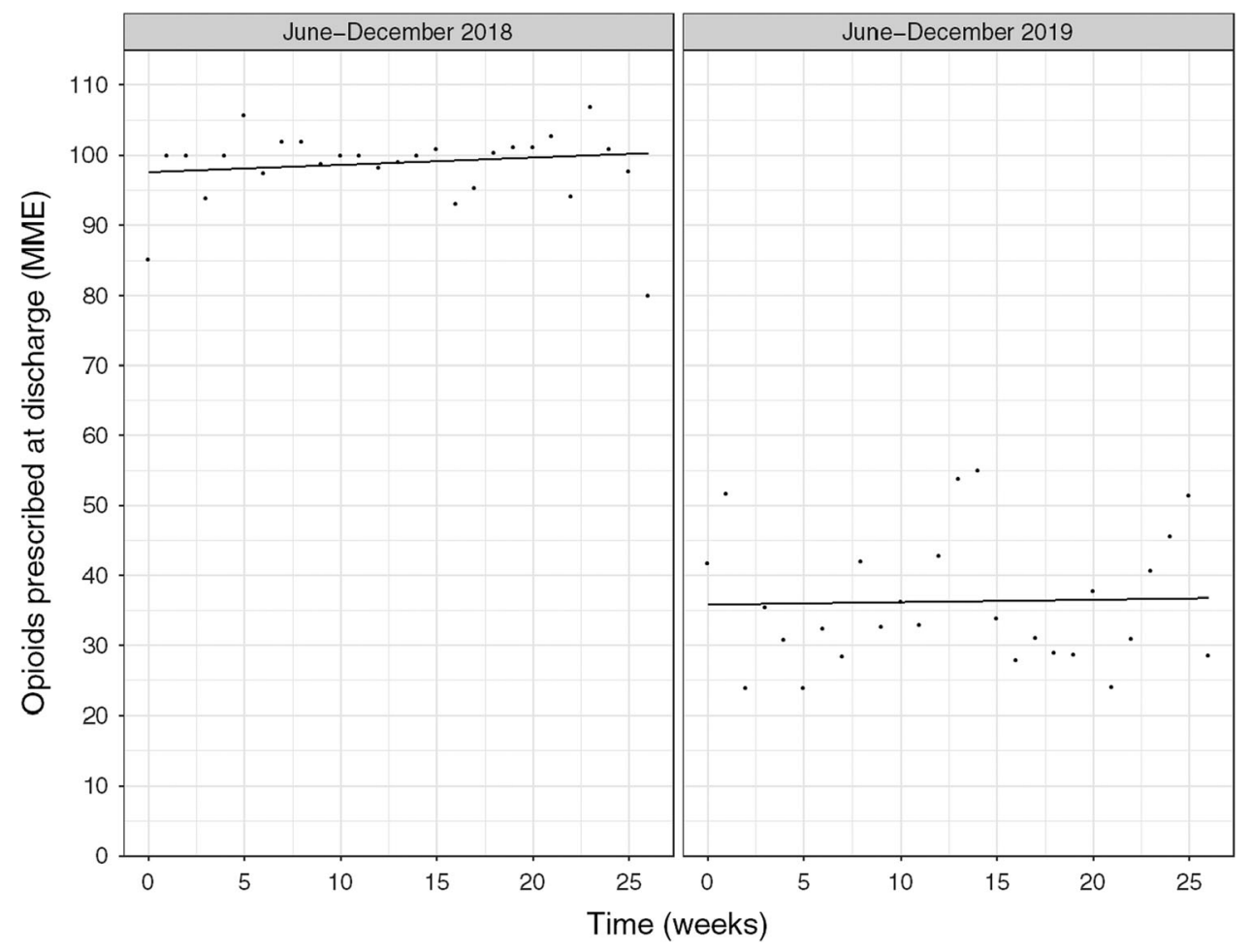

Table 3 Unadjusted and adjusted opioid use in hospital and prescription patterns before and after a bundled quality improvement intervention aimed at reducing discharge opioid prescribing

\begin{tabular}{|c|c|c|c|c|}
\hline Outcome & $\begin{array}{l}\text { Pre intervention } \\
n=1,352\end{array}$ & $\begin{array}{l}\text { Post intervention } \\
n=1,226\end{array}$ & $P$ value & Difference $(95 \% \mathrm{CI})$ \\
\hline Patients receiving discharge prescription for opioids & $1,320(97.6 \%)$ & $661(53.9 \%)$ & $<0.001$ & $\begin{array}{l}-43.7(-46.7 \text { to } \\
-40.7)\end{array}$ \\
\hline $\begin{array}{l}\text { Quantity of opioids in discharge prescription (MME), median } \\
\text { [IQR] }\end{array}$ & $100[100-100]$ & $25[0-50]$ & $<0.001$ & \\
\hline Patients using opioids in hospital for breakthrough pain & $547(40.5 \%)$ & $465(37.9 \%)$ & 0.20 & $-2.5(-1.3$ to 6.4$)$ \\
\hline Adjusted average discharge prescription estimates in MME & $\begin{array}{l}97.6(92.8 \text { to } \\
102.4)\end{array}$ & $\begin{array}{l}35.8(26.5 \text { to } \\
45.1)\end{array}$ & $<0.001$ & $\begin{array}{l}-61.7(-72.2 \text { to } \\
-51.3)\end{array}$ \\
\hline
\end{tabular}

All numbers are $n(\%)$ unless otherwise specified. $P$ values and differences are calculated from the Chi square test and Wilcoxon rank sum test. Normality was determined using the Shapiro-Wilk test.

$\mathrm{CI}=$ confidence interval; $\mathrm{MME}=$ morphine milliequivalents; $\mathrm{OR}=$ odds ratio; $\mathrm{SD}=$ standard deviation

noticed a culture shift where nurses were no longer routinely requesting opioid discharge prescriptions for patients. Additional studies that evaluate patient expectations around pain control would help identify areas for improvement. To date, there are no Canadian guidelines on opioid prescription cut-offs post Cesarean delivery. Instead, guidelines suggest a shared decisionmaking approach should be used to achieve pain control using the lowest dose and shortest duration possible. ${ }^{29}$ Despite this, experts have recommended a maximum discharge prescription of 75 MME for opioid-naïve patients following uncomplicated Cesarean delivery. ${ }^{30}$
Our median [IQR] opioid prescription post intervention was well below this threshold at 25 [0-50] MME, which is consistent with evidence that fewer opioids may be required in this patient population than previously recommended. ${ }^{15-17} \mathrm{~A}$ national guideline that utilizes evidence-based interventions such as electronic prescriptions for opioid prescribing would be helpful in establishing a standardized approach in reducing overprescribing.

For similar QI interventions, we recommend additional training for experienced prescribers, and implementing electronic prescriptions with lower quantities of opioids. 
Table 4 Prescribing patterns by provider and specialty before and after a bundled quality improvement intervention aimed at reducing discharge opioid prescribing

\begin{tabular}{|c|c|c|c|c|}
\hline & \multicolumn{2}{|c|}{$\begin{array}{l}\text { Pre intervention } \\
n=1,352\end{array}$} & \multicolumn{2}{|c|}{$\begin{array}{l}\text { Post intervention } \\
n=1,226\end{array}$} \\
\hline & $n$ & MME & $n$ & MME \\
\hline \multicolumn{5}{|l|}{ Prescriber year } \\
\hline PGY-1 & 277 & $100.2(9.0)$ & 252 & $27.2(40.2)$ \\
\hline PGY-2 & 428 & $99.6(15.5)$ & 391 & $39.4(41.1)$ \\
\hline PGY-3 & 201 & $93.2(27.3)$ & 199 & $40.0(43.4)$ \\
\hline PGY-4 & 116 & $99.6(16.8)$ & 30 & $30.0(46.1)$ \\
\hline PGY-5 & 32 & $101.6(8.8)$ & 59 & $45.0(30.6)$ \\
\hline Fellow, maternal fetal medicine & 108 & $102.8(35.4)$ & 114 & $45.6(61.3)$ \\
\hline Fellow, advanced obstetrical & 178 & $98.6(17.2)$ & 166 & $26.8(38.4)$ \\
\hline Staff physician & 4 & $112.5(25.0)$ & 11 & $55.0(40.3)$ \\
\hline$P$ value & \multicolumn{2}{|l|}{$<0.001$} & \multicolumn{2}{|l|}{$<0.001$} \\
\hline \multicolumn{5}{|l|}{ Prescriber specialty } \\
\hline Obstetrics and gynecology & 1,020 & 98.5 (21.6) & 957 & $38.4(43.6)$ \\
\hline Family medicine & 175 & $101.4(11.3)$ & 112 & $25.1(38.3)$ \\
\hline Radiology & 45 & $100.0(0.0)$ & 14 & $39.3(58.2)$ \\
\hline Anesthesiology & 104 & $99.0(9.8)$ & 139 & $28.5(42.6)$ \\
\hline Nurse practitioner & 8 & $100.0(0.0)$ & 4 & $16.2(19.7)$ \\
\hline$P$ value & 0.68 & & 0.002 & \\
\hline
\end{tabular}

All numbers are mean (standard deviation) unless otherwise specified. $P$ values are from the Kruskal-Wallis test by ranks and Wilcoxon rank sum test. Prescriber year refers to level of training in any program specialty while prescriber specialty refers to specialty at any stage of training. MME = morphine milliequivalents; $\mathrm{PGY}=$ postgraduate year

Table 5 Opioids used in hospital and prescribed at discharge before and after a bundled quality improvement intervention aimed at reducing discharge opioid prescribing

\begin{tabular}{|c|c|c|c|c|}
\hline \multirow[t]{2}{*}{ Opioid use in hospital } & \multicolumn{2}{|c|}{$\begin{array}{l}\text { Pre intervention } \\
n=1,352\end{array}$} & \multicolumn{2}{|c|}{$\begin{array}{l}\text { Post intervention } \\
n=1,226\end{array}$} \\
\hline & No & Yes & No & Yes \\
\hline$n$ & 805 & 547 & 761 & 465 \\
\hline \multicolumn{5}{|c|}{ Patients receiving discharge prescription for opioids (\%) } \\
\hline No & $20(2.5 \%)$ & $12(2.2 \%)$ & $448(58.9 \%)$ & $117(25.2 \%)$ \\
\hline Yes & $785(97.5 \%)$ & $535(97.8 \%)$ & $313(41.1 \%)$ & $348(74.8 \%)$ \\
\hline$P$ value & 0.87 & & $<0.001$ & \\
\hline
\end{tabular}

All numbers are $n(\%)$ unless otherwise specified. $P$ values are from the Chi square test

Our results add to a rapidly expanding knowledge that QI initiatives are associated with reduced opioid prescribing. Since Cesarean deliveries are the most common inpatient surgeries performed in Canada and the USA, reducing opioid prescribing in this patient population will likely have a large impact on reducing the overall number of opioids in North America.

Our findings should be interpreted in the context of several limitations. Firstly, our model did not account for confounding factors and baseline differences in intervention groups that were not available from patient records, such as secular, institutional or practice changes outside the QI intervention. We used a segmented regression model and interrupted time series design with weekly periods to minimize any bias from potential confounding of these variables with the intervention. Secondly, our interventions were bundled, which makes it difficult to discern which interventions contributed the 
most to opioid reduction. Thirdly, the retrospective nature of data selection may have increased the risk of missing eligible cases that had incomplete outcome data thereby introducing selection bias. In our hospital, there was a transition from paper to electronic prescriptions in 2019. This resulted in missing outcome data for 70 patients that were likely given paper prescriptions. It is possible that prescribers who provided these discharge prescriptions were prescribing opioids in larger amounts as they were not limited by standard electronic discharge prescriptions. Nevertheless, a large percentage $(97 \%)$ of all patients who underwent Cesarean delivery during the study period were still included in our analysis. Lastly, our data set did not include information on patient-reported outcomes and therefore we were unable to assess whether our intervention affected patient pain control and/or satisfaction. Nevertheless, there were no visits to our postnatal assessment clinic for inadequate pain control and no increased calls or visits noted by the obstetricians. Further research should focus on patient-reported outcomes.

\section{Conclusion}

This study shows that a bundled QI intervention (trainee, nursing and patient education, posters, and electronic prescriptions) was associated with a sustained reduction in amount of opioid prescribed post-Cesarean delivery. Individualizing discharge prescriptions based on opioid use in hospital should be further investigated. Therefore, we recommend that the potential for implementation of similar interventions be assessed across obstetrical units in Canada and the USA.

\begin{abstract}
Author contributions AS contributed to all aspects of this manuscript, including study conception and design; acquisition, analysis, and interpretation of data; and drafting the article. IL contributed to the study design; acquisition, analysis, interpretation of data; and drafting the article. JM contributed to analysis of data, interpretation of data, and drafting the article. DF contributed to study design, interpretation of data, and drafting of the article. SG contributed to study conception, interpretation of data, and drafting the article.
\end{abstract}

Acknowledgements The authors gratefully acknowledge the Institute for Safe Medication Practices (ISMP) Canada and the Canadian Patient Safety Institute for their help in creating the patient handout and Mount Sinai Hospital for providing the prescribing opioid pain medication poster.

Competing interests None declared.

Funding statement This project was jointly funded by the Generalist Division, Department of Obstetrics and Gynaecology and the Department of Anesthesiology and Pain Medicine at Mount Sinai Hospital.
Editorial reponsibility This submission was handled by Dr. Stephan K.W. Schwarz, Editor-in-Chief, Canadian Journal of Anesthesia/Journal canadien d'anesthésie.

Open Access This article is licensed under a Creative Commons Attribution-NonCommercial 4.0 International License, which permits any non-commercial use, sharing, adaptation, distribution and reproduction in any medium or format, as long as you give appropriate credit to the original author(s) and the source, provide a link to the Creative Commons licence, and indicate if changes were made. The images or other third party material in this article are included in the article's Creative Commons licence, unless indicated otherwise in a credit line to the material. If material is not included in the article's Creative Commons licence and your intended use is not permitted by statutory regulation or exceeds the permitted use, you will need to obtain permission directly from the copyright holder. To view a copy of this licence, visit http://creativecommons.org/licenses/ by-nc/4.0/.

\section{References}

1. International Narcotics Control Board. Narcotic Drugs Estimated World Requirements for 2018 Statistics for 2016. 2017. Available from URL: www.incb.org (accessed September 2021).

2. Centers for Disease Control and Prevention; National Center for Injury Prevention and Control. 2018 Annual Surveillance DrugRelated Risks and Outcomes- United States. Available from URL: $\quad$ https://www.cdc.gov/drugoverdose/pdf/pubs/2018-cdcdrug-surveillance-report.pdf (accessed September 2021).

3. Canadian Institute for Health Information. Opioid Prescribing in Canada: How Are Practices Changing? 2019. Available from URL: https://www.cihi.ca/sites/default/files/document/opioidprescribing-canada-trends-en-web.pdf (accessed September 2021).

4. Ladha KS, Neuman MD, Broms $G$, et al. Opioid prescribing after surgery in the United States, Canada, and Sweden. JAMA Netw Open 2019; DOI: https://doi.org/10.1001/jamanetworkopen.2019. 10734.

5. Alam A, Gomes T, Zheng H, Mamdani MM, Juurlink DN, Bell $C M$. Long-term analgesic use after low-risk surgery: a retrospective cohort study. Arch Intern Med 2012; 172: 425-30.

6. Clarke H, Soneji N, Ko DT, Yun L, Wijeysundera DN. Rates and risk factors for prolonged opioid use after major surgery: population based cohort study. BMJ 2014; DOI: https://doi.org/ 10.1136/bmj.g1251.

7. Calcaterra SL, Yamashita TE, Min SJ, Keniston A, Frank JW, Binswanger IA. Opioid prescribing at hospital discharge contributes to chronic opioid use. J Gen Intern Med 2016; 31: 478-85.

8. Canadian Centre on Substance Use and Addiction. Joint Statement of Action to Address the Opioid Crisis: A Collective Response (Annual Report 2016-2017). Available from URL: https://www.ccsa.ca/joint-statement-action-address-opioid-crisiscollective-response-annual-report-2016-2017 (accessed September 2021).

9. Canadian Public Health Association. The Opioid Crises in Canada. December 2016. Available from URL: https://www. cpha.ca/sites/default/files/uploads/policy/positionstatements/ opioid-positionstatement-e.pdf (accessed September 2021).

10. Canadian Centre on Substance Use and Addiction. First Do No Harm: Responding to Canada's Prescription Drug Crisis (Report). 
2013. Available from URL: https://www.ccsa.ca/first-do-noharm-responding-canadas-prescription-drug-crisis-report (accessed September 2021).

11. Health Quality Ontario. Recommendations for Adoption: Opioid Prescribing for Acute Pain. Recommendations to enable widespread adoption of this quality standard. Available from URL: http://www.hqontario.ca/Portals/0/documents/evidence/ quality-standards/qs-opioid-acute-pain-recommendations-foradoption-en.pdf (accessed September 2021).

12. Opioid Acute Pain Prescribing Working Group. Call to Action: Adult Opioid Postoperative Prescribing. September 2019. Available from URL: https://www.icsi.org/wp-content/uploads/ 2019/09/Opioid-PostOp-CTA_Final-090519.pdf (accessed September 2021).

13. Canadian Institute for Health Information. Inpatient Hospitalizations, Surgeries, Newborns and Childbirth Indicators, 2018-2019. Available from URL: https://secure.cihi. $\mathrm{ca} /$ estore/productFamily.htm?pf $=\mathrm{PFC} 4179 \&$ lang $=$ fr\&media $=0$ (accessed 31 Jul2020).

14. McDermott, KW., Freeman, WJ., Elixhauser A. Most Common Operations During Inpatient Stays - HCUP Fast Stats. Available from URL: https://www.hcup-us.ahrq.gov/faststats/ NationalProceduresServlet (accessed September 2020).

15. Gold S, Figueiro-Filho E, Agrawal S, Selk A. Reducing the number of opioids consumed after discharge following elective cesarean delivery: a randomized controlled trial. J Obstet Gynaecol Can 2020; DOI: https://doi.org/10.1016/j.jogc.2020. 02.123.

16. Bartels K, Mayes LM, Dingmann C, Bullard KJ, Hopfer CJ, Binswanger IA. Opioid use and storage patterns by patients after hospital discharge following surgery. PLoS One 2016; DOI: https://doi.org/10.1371/journal.pone.0147972.

17. Bateman BT, Cole NM, Maeda A, et al. Patterns of opioid prescription and use after cesarean delivery. Obstet Gynecol 2017; 130: 29-35.

18. Osmundson SS, Schornack LA, Grasch JL, Zuckerwise LC, Young $J L$, Richardson $M G$. Postdischarge opioid use after cesarean delivery. Obstet Gynecol 2017; 130: 36-41.

19. Holland E, Bateman BT, Cole $N$, et al. Evaluation of a quality improvement intervention that eliminated routine use of opioids after cesarean delivery. Obstet Gynecol 2019; 133: 91-7.
20. Mehraban SS, Suddle $R$, Mehraban S, et al. Opioid-free multimodal analgesia pathway to decrease opioid utilization after cesarean delivery. J Obstet Gynaecol Res 2020; DOI: https://doi.org/10.1111/jog.14582.

21. Voelker KA, Schauberger C. Academic detailing for postpartum opioid prescribing. J Am Board Fam Med 2018; 31: 944-6.

22. McHugh ML. The chi-square test of independence. Biochem Med (Zagreb) 2013; 23: 143-9.

23. Ogrinc $G$, Davies L, Goodman D, Batalden P, Davidoff $F$, Stevens D. SQUIRE 2.0 (Standards for QUality Improvement Reporting Excellence): revised publication guidelines from a detailed consensus process. BMJ Qual Saf 2016; 25: 986-92.

24. National Opioid Use Guideline Group (NOUGG). Canadian Guideline for Opioid Use for Pain — Appendix B-8: Opioid Conversion and Brand Availability in Canada. Available from URL: http://nationalpaincentre.mcmaster.ca/opioid/ (accessed September 2021).

25. Wong BM, Levinson $W$, Shojania $K G$. Quality improvement in medical education: current state and future directions. Med Educ 2012; 46: 107-19.

26. Montoy JC, Coralic Z, Herring AA, Clattenburg EJ, Raven MC Association of default electronic medical record settings with health care professional patterns of opioid prescribing in emergency departments: a randomized quality improvement study. JAMA Intern Med 2020; 180: 487-93.

27. Nanji JA, Guo N, Riley ET, Faulkner B, Do C, Carvalho B. Evaluation of opioid use with split doses of oral opioids in a postcesarean delivery analgesia order set. Obstet Gynecol 2019; 134: $120-7$

28. Ontario Drug Policy Research Network. Ontario Prescription Opioid Tool. https://odprn.ca/ontario-opioid-drug-observatory/ ontario-prescription-opioid-tool/ (accessed September 2021).

29. Anonymous. ACOG Committee Opinion No. 742: Postpartum pain management. Obstet Gynecol 2018; 132: e35-43.

30. Overton HN, Hanna MN, Bruhn WE, et al. Opioid-prescribing guidelines for common surgical procedures: an expert panel consensus. J Am Coll Surg 2018; 227: 411-8.

Publisher's Note Springer Nature remains neutral with regard to jurisdictional claims in published maps and institutional affiliations. 